\title{
H CANYON PROCESSING IN CORRELATION WITH F/H ANALYTICAL LABS
}

\author{
Emily Weinheimer
}

SUMMER 2012

Savannah River National Laboratory

Savannah River Nuclear Solutions

Aiken, SC 29808 


\section{DISCLAIMER}

This work was prepared under an agreement with and funded by the U.S. Government. Neither the U.S. Government or its employees, nor any of its contractors, subcontractors or their employees, makes any express or implied:

1. warranty or assumes any legal liability for the accuracy, completeness, or for the use or results of such use of any information, product, or process disclosed; or

2. representation that such use or results of such use would not infringe privately owned rights; or

3. endorsement or recommendation of any specifically identified commercial product, process, or service.

Any views and opinions of authors expressed in this work do not necessarily state or reflect those of the United States Government, or its contractors, or subcontractors.

Printed in the United States of America

Prepared for

U.S. Department of Energy 


\section{EXECUTIVE SUMMARY}

Management of radioactive chemical waste can be a complicated business. H Canyon and $\mathrm{F} / \mathrm{H}$ Analytical Labs are two facilities present at the Savannah River Site in Aiken, SC that are at the forefront. In fact $\mathrm{H}$ Canyon is the only large-scale radiochemical processing facility in the United States and this processing is only enhanced by the aid given from $\mathrm{F} / \mathrm{H}$ Analytical Labs. As $\mathrm{H}$ Canyon processes incoming materials, $\mathrm{F} / \mathrm{H}$ Labs provide support through a variety of chemical analyses. Necessary checks of the chemical makeup, processing, and accountability of the samples taken from $\mathrm{H}$ Canyon process tanks are performed at the labs along with further checks on waste leaving the canyon after processing.

Used nuclear material taken in by the canyon is actually not waste. Only a small portion of the radioactive material itself is actually consumed in nuclear reactors. As a result various radioactive elements such as Uranium, Plutonium and Neptunium are commonly found in waste and may be useful to recover. Specific processing is needed to allow for separation of these products from the waste. This is H Canyon's specialty.

Furthermore, H Canyon has the capacity to initiate the process for weapons-grade nuclear material to be converted into nuclear fuel. This is one of the main campaigns being set up for the fall of 2012 . Once usable material is separated and purified of impurities such as fission products, it can be converted to an oxide and ultimately turned into commercial fuel. The processing of weapons-grade material for commercial fuel is important in the necessary disposition of plutonium.

Another processing campaign to start in the fall in H Canyon involves the reprocessing of used nuclear fuel for disposal in improved containment units. The importance of this campaign involves the proper disposal of nuclear waste in order to ensure the safety and well-being of future generations and the environment.

As processing proceeds in the fall, $\mathrm{H}$ Canyon will have a substantial number of samples being sent to F/H Labs. All analyses of these samples are imperative to safe and efficient processing. The important campaigns to occur would be impossible without feedback from analyses such as chemical makeup of solutions, concentrations of dissolution acids and nuclear material, as well as nuclear isotopic data. The necessity of analysis for radiochemical processing is evident. Processing devoid of F/H Lab's feedback would go against the ideals of a safety-conscious and highly accomplished processing facility such as H Canyon. 


\section{TABLE OF CONTENTS}

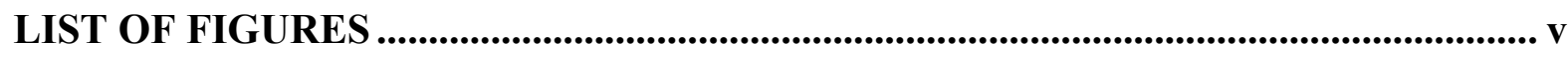

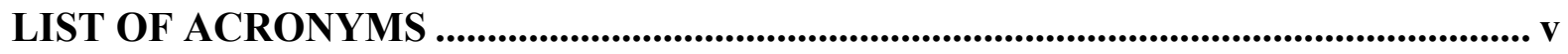

1.0 INTRODUCTION AND BACKGROUND............................................................... 1

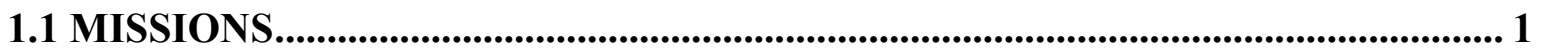

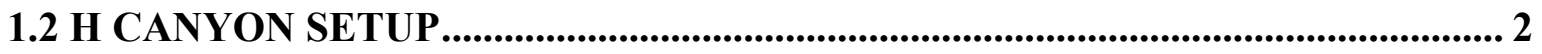

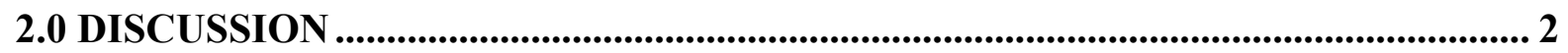

2.1 H CANYON PROCESSING.............................................................................. 2

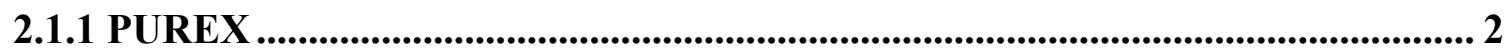

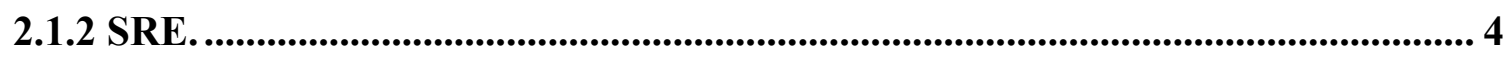

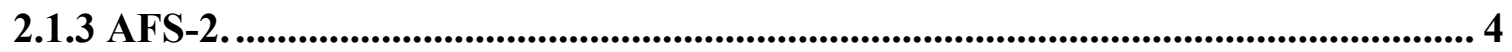

2.2 LAB ANALYSIS.................................................................................................................... 4

2.2.1 Chemical Makeup Analysis........................................................................... 5

2.2.2 Accountability Analysis ....................................................................................................... 5

2.2.3 Processing Analysis ............................................................................................................. 6

2.2.4 Waste Analysis....................................................................................................... 6

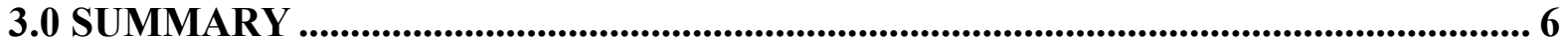

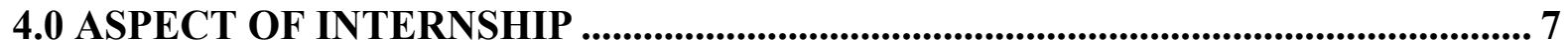

4.1 PROJECT OBJECTIVE. ................................................................................ 7

4.2 CHEMICAL ENGINEERING CLASSES ........................................................ 7

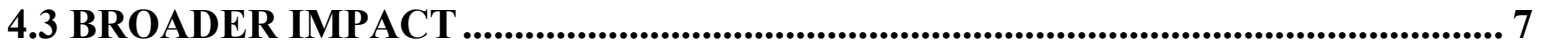

4.3.1 Society Impacts ............................................................................................................ 7

4.3.2 Contemporary Issues ....................................................................................... 8

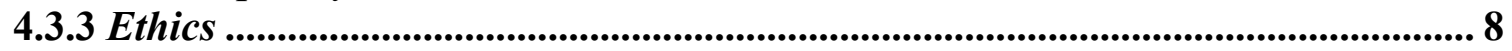

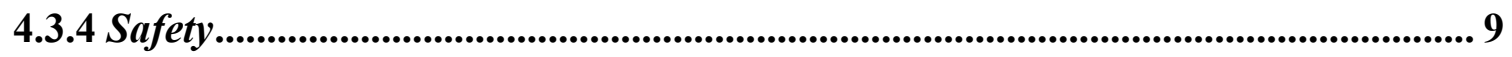

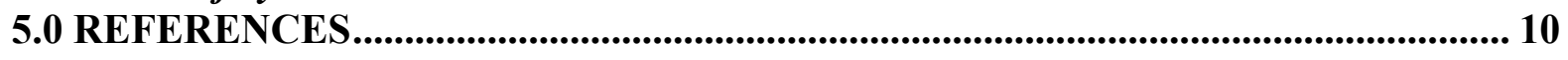

6.0 ACKNOLEDGEMENTS ................................................................................................. 10 


\section{LIST OF FIGURES}

Figure 1. H Canyon Modified PUREX Process Flow Diagram...........................

\section{LIST OF ACRONYMS}

$\begin{array}{ll}\text { AFS-2 } & \text { Alternate Feed Stream 2 } \\ \text { BBS } & \text { Behavior-Based Safety } \\ \text { CE } & \text { Chemical Engineering } \\ \text { DHEC } & \text { Department of Health and Environmental Control } \\ \text { DOE } & \text { Department of Energy } \\ \text { DWPF } & \text { Defense Waste Processing Facility } \\ \text { HBL } & \text { HB-Line } \\ \text { HEU } & \text { Highly Enriched Uranium }>20 \% \\ \text { ICP-AES } & \text { Inductively Coupled Plasma }- \text { Atomic Emission Spectroscopy } \\ \text { ICP-MS } & \text { Inductively Coupled Plasma - Mass Spectroscopy } \\ \text { IDMS } & \text { Isotope Dilution Mass Spectrometry } \\ \text { ISE } & \text { Ion Selectivity Electrode } \\ \text { KPA } & \text { Kinetic Phosphorescence Analyzer } \\ \text { LEU } & \text { Low Enriched Uranium }<20 \% \\ \text { MFFF } & \text { Mixed Oxide Fuel Fabrication Facility } \\ \text { MOX } & \text { Mixed Oxide Facility } \\ \text { NASA } & \text { National Aeronautics and Science Administration } \\ \text { PPE } & \text { Personal Protective Equipment } \\ \text { Pu } & \text { Plutonium } \\ \text { PUREX } & \text { Plutonium and Uranium Extraction } \\ \text { SRE } & \text { Sodium Reactor Experiment } \\ \text { SRNL } & \text { Savannah River National Lab } \\ \text { SRS } & \text { Savannah River Site } \\ \text { TBP } & \text { Tributyl Phosphate } \\ \text { TIMS } & \text { Thermal Ionization Mass Spectroscopy } \\ \text { U } & \text { Uranium } \\ \text { UNF } & \text { Used Nuclear Fuel } \\ \text { WAC } & \text { Waste Acceptance Criteria } \\ & \end{array}$




\subsection{INTRODUCTION AND BACKGROUND}

Environmental Stewardship, Clean Energy, National Security. These are the three ideals that Savannah River National Labs (SRNL), as well as Enterprise SRS, works toward on a daily basis as demonstrated by the ever lengthening list of accomplishments made by the labs. In correspondence with the labs, Savannah River Site (SRS) is one of the few places in the US where chemical nuclear engineering is really a focal point and has been since its construction. The ability to stabilize nuclear materials such as uranium, plutonium and neptunium on such a large scale solely belongs to $\mathrm{H}$ Canyon as a one of a kind processing facility on the site. The peak of its use was during the cold war; however, new missions have given SRS a reason to again use the Canyon's unique capabilities. H Canyon is supported by $\mathrm{F} / \mathrm{H}$ Analytical Labs which keeps $\mathrm{H}$ Canyon processing in check. Without $\mathrm{F} / \mathrm{H}$ Labs, H Canyon would be without its most fundamental resource.

\subsection{MISSIONS}

Construction of the site and particularly H Canyon first began in the 1950s as the US government turned its attention to the cold war. The massive concrete building, resembling a canyon, started operations in 1955. The main ability of $\mathrm{H}$ Canyon is to recover uranium, plutonium and neptunium from enriched uranium fuel rods encased in aluminum. Throughout the cold war, H Canyon operated recovering materials from used nuclear fuel (UNF) for reuse. However, at the end of the war in 1992, $\mathrm{H}$ Canyon changed their mission to stabilizing remaining highly enriched uranium (HEU) materials present at SRS. One of H Canyon's most well-known accomplishments of that time is the purification of plutonium 238 for use in 30 of the National Aeronautics and Space Administration (NASA) missions, including the ongoing Cassini mission.

By 2001, the Department of Energy (DOE) realized the potential for blending down HEU to low enriched uranium (LEU). H Canyon began that mission with the Tennessee Valley Authority as the recipient of LEU for commercial use. In 2006, H Canyon began a mission to blend down UNF, now sourced from domestic and foreign research reactors. The 2006 UNF mission has been completed; however, a new UNF mission is being set up for the fall of 2012. This new mission involves processing sodium reactor experiment (SRE) UNF, some of which was transferred to the site soon after the SRE from Santa Susana Field Laboratory in California was shutdown. The plutonium found in SRE UNF is of such a low grade that it is being processed for removal as waste. Once H Canyon processes the SRE UNF, it will be temporarily stored until eventual movements toward vitrification at another SRS facility.

Another mission currently in view for fall of 2012 is Alternate Feed Stream 2 (AFS-2). This mission is being undertaken to recover potentially usable plutonium at $\mathrm{H}$ Canyon facilities and HB-Line (HBL), a facility located on top of the canyon. Once purified and recovered in the form of plutonium oxide, it will be sent to the new Mixed Oxide Fuel Fabrication Facility (MFFF) to be blended with uranium oxides. MFFF is responsible for forming fuel pellets from the mixed oxides for use as commercial reactor fuel. This new mission is an important step in the United States' disposal of surplus weapons-grade plutonium. 


\subsection{H CANYON SETUP}

The processing of nuclear material is a challenge that not many places in the world can truly say they have accomplished. Radiation exposure is a significant concern that $\mathrm{H}$ Canyon has overcome through the use of overhead cranes and the construction of a six-foot thick concrete walls separating the workers from the processing areas. Cranes are operated remotely to minimize exposure and furthermore allow for movement of piping between the tanks, making the processing area flexible to changing missions. All processing controls are also operated remotely through a control room that sits between the two processing areas of the canyon. Tanks where nuclear materials are processed are under ground level and have cell covers, further reducing exposure.

\subsection{DISCUSSION}

\subsection{H CANYON PROCESSING}

$\mathrm{H}$ Canyon processing as stated before, is extremely flexible as to what type of missions and campaigns can be taken on. PUREX processing is the main set up for processing done in the canyon. Various steps of PUREX can be carried out based on what material is being processed and the desired use of the products being processed. HEU blend down is a common process that normally uses most of the PUREX processing model. However purification of material intended for waste such as SRE mission uses only the beginning steps of PUREX in H Canyon before being stored for future work. The AFS-2 processing also only uses the beginning steps of the PUREX processing model before being sent to HBL for purification for eventual use in MFFF.

\subsubsection{PUREX}

Normal processing of nuclear materials that used to occur in $\mathrm{H}$ Canyon is a form of the PUREX process as seen in Figure 1. PUREX is a process for plutonium and uranium extraction and is used to recover plutonium and uranium from used nuclear fuel. The first step in recovery is the dissolution of the uranium fuel rods encased in aluminum. Dissolution must occur in a dissolver containing nitric acid that is heated to a boil and following that, the uranium fuel bundles are added and dissolved. The outcoming solution contains alumnium, uranium, plutonium, neptunium, mercury, fission products, and other impurities. Once dissolution is complete, the next step is head end processing. Head end involves the addition of gelatin to the solution and then the use of a centrifuge to remove unwanted materials. The gelatin traps silicates and other unwanted materials in what is called the 'cake'. The gelatin-cake is removed and the remaining liquid solution continues through the process. It is necessary to remove silicon as it interferes with the separations chemistry performed later on. Silicates are used in the processing of aluminum which has been the standard cladding used in nuclear material prodcution for decades.

Follwing head end, the first cycle of solvent extraction is prepared. All extraction is done using Tributyl Phosphate (TBP). This first cycle is done in three separate stages. An organic layer of TBP dissolved in an n-paraffin solvent is mixed with the feed stream in the first bank. As the concentration of nitric acid is increased, the desired uranium/neptunium enters the organic TBP layer leaving main impurities like aluminum nitrate and mercury as well as minor impurities like plutonium and fission products in the acid layer. In the second bank the acid concentration is lowered enough to allow neptunium to drop out of the TBP layer, leaving only uranium. Then, in the third bank, an 
extremely diluted nitric acid solution is added, lowering the overall concentration of nitric acid. This allows for the uranium to drop out of the TBP organic layer and into the acid layer. The second uranium cycle is simliar. However since the neptunium was separated out already, the middle bank is not needed.

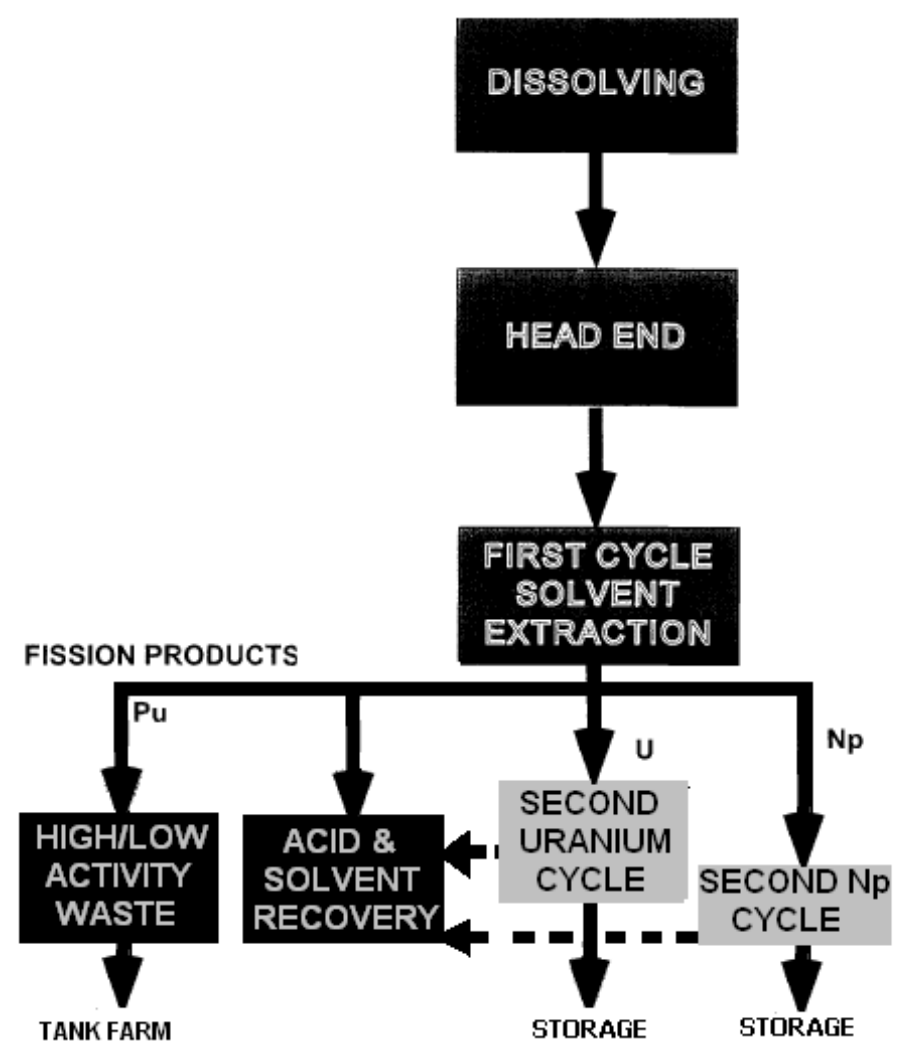

Figure 1. H Canyon Modified PUREX Process Flow Diagram

Additional separation of impurities of the uranium solution, if needed, occurs in the second uranium cycle. Once again, impurities are removed in the first stage of second bank. The second bank allows for the removal of uranium into a nitric acid solution yet again. The uranium can then be stored as a uranyl nitrate solution. Neptunium, once removed in the first uranium cycle, can also be purified in a cycle similar to that of the second uranium cycle. However, the concentration of TBP in the solvent is adjusted for better recovery of neptunium.

Once the main impurities have been removed in acid as waste, the acid goes through a purification cycle in distillation columns and is reused in the process. The solvent used in processing is also recovered and reused. It is only replaced after one or two years of use when the TBP degradation is too substantial to allow for efficient separation.

Further waste processing occurs in H Canyon. The solution of mostly aluminum nitrate, mercury, plutonium and fission products removed from the first solvent extraction cycle are sent to high activity waste processing where they are run through evaporators to be concentrated down. Once evaporation has occurred, waste streams are removed to the tank farm where waste is stored to await 
being placed in a glass matrix for permanent disposition. Low activity waste, where the constituents are not as 'hot' radioactively, is processed in the same manner although stored differently once sent to the tank farm.

\subsubsection{SRE}

SRE processing in H Canyon is fairly simple and only encompasses the first step of the PUREX process. Since this sodium-clad UNF is mostly low grade uranium and thorium, the UNF must only be dissolved in a boiling nitric acid solution. Once dissolution is complete, the stream will be sent to the tank farm. Future processing of the waste involves vitrification where the waste is solidified in a glass matrix at the Defense Waste Processing Facility (DWPF). The processing of SRE spent fuel is necessary to offer for more reliable future containment.

\subsubsection{AFS-2}

Processing for AFS-2 relies on a small part of the PUREX process. The use of dissolvers and other storage tanks are essential before moving solutions to HBL. The dissolution follows the PUREX process with plutonium as the target material being processed. Dissolutions are carried out with plutonium bundles being dissolved in a boiling nitric acid solution which, also contains fluorides to aid in dissolution. Once fuel rods are dissolved, aluminum nitrate is added to the protect stainless steel tanks from corrosion by fluoride. When all material is accounted for, it is sent to HBL to complete conversion from plutonium nitrate to plutonium oxide. Two waste streams are fed back to $\mathrm{H}$ Canyon from HBL. One is the column waste stream and the other filtrate waste stream. Both are further processed in $\mathrm{H}$ Canyon and depending on the amount of plutonium still present, it may be sent to HBL for further recovery. If no further plutonium is to be recovered, it enters either high or low level waste processing depending on the constituents of the waste stream. Once processed, streams are directed to the tank farm.

\subsection{LAB ANALYSIS}

Although AFS-2 processing in the canyon is limited to dissolutions and returning waste stream from $\mathrm{HBL}$, the analysis is quite extensive. Set sample points for dissolution, column waste and filtrate waste processing will allow for samples to be routinely taken and sent to F/H Analytical Labs. When collecting samples, there are always two samples taken for each sample point. The reason being to ensure that samples pulled are a suitable and consistent representation of the material in the tank, as determined by verification analyses in $\mathrm{F} / \mathrm{H}$ Labs.

Verification analyses require three measurements before further analysis is performed. The first is a visual analysis of samples for color, presence of solids, turbidity, integrity of the container, etc. The second is the verification of correct volume of material present with original volume recorded. The third is a solution density analysis using Anton Paar Density Meter. All analyses are conducted on both samples and the density is measured and compared between the two samples. If the density comparison is significantly different, samples must be taken again as this is an indication of improper or incomplete mixing. If the visual and volumetric measurements are unusual, samples may need to be retaken as these signs may be indications of insufficient sample volume size, improper sampling technique, or process upset. If all measurements are found to be positive, these samples, representative of tank material, can be analyzed further at the lab. 
Samples in the lab have one of four analysis codes that they can be classified under: chemical makeup, accountability, processing, and waste. Each type of sample code provides for a different set of analyses to be done in the lab.

\subsubsection{Chemical Makeup Analysis}

This analysis is only done for dissolver samples before dissolution occurs. It is necessary to check if the proper constituents are present to dissolve nuclear material. A further check is to make sure that the solution is not too corrosive to the dissolver tank due to the presence of acid and fluoride which are needed for dissolution.

Analyses done for the chemical makeup code generally consist of free acid, fluoride, and boron analysis. Free acid titrations are performed to determine the concentration of nitric acid in the dissolver. If nitric acid is at the wrong concentration, the fuel rods may not dissolve completely. Adjustments can be made to correct before dissolution. Fluoride analysis is conducted using an ion selective electrode (ISE). A certain amount of fluoride is essential in aiding in dissolution of aluminum clad bundles and is normally used for plutonium dissolutions in general. However, a large enough presence of fluoride can significantly shorten the service life of the stainless steel tanks. Therefore, if its concentration is too high or too low in the dissolution tank, the solution must be altered. An inductively coupled plasma - atomic emissions spectrometer (ICP-AES) is used for boron analysis. The presence of boron is extremely important for handling of nuclear materials. Boron acts as a neutron poison meaning that if the correct desired amount of boron is present, it will keep the nuclear material from going critical. If not enough boron is found to be present in the dissolver, more must be added to maintain safety conditions. Boron along with tank geometry and limited concentrations provides that there are always multiple independent controls used to prevent any credible criticality scenario that must be maintained at all times.

\subsubsection{Accountability Analysis}

The tracking and physical inventory of nuclear material is the main reason for accountability analysis. This type of analysis is necessary for safety and safeguards issues. If it is found that these accountability analyses do not match up within a certain range of the previous accountability analysis data, this would indicates a potential loss or diversion of nuclear materials. These strict checks are common to maintain accountability of all nuclear materials on site.

The accountability code indicates analysis by free acid, fluoride, and boron analysis, similar to the chemical makeup code. It also includes uranium (U) by Chemcheck, plutonium $(\mathrm{Pu})$ isotope dilution mass spectrometry (IDMS), and Pu isotopic analysis. U by Chemcheck is an analysis conducted using the kinetic phosphorescence analyzer (KPA) which checks for low level uranium. For AFS-2, it is necessary that only trace amounts of $U$ are found in samples since plutonium is the nuclear material being targeted for recovery. Pu IDMS is conducted using the thermal ionization mass spectrometer (TIMS). This is a high accuracy and high precision instrument and is used to analyze concentration of $\mathrm{Pu}$. Pu isotopic analysis is also conducted using TIMS, which can make a distinction between different isotopes by weight percent. This is necessary to ensure that the correct isotopes of $\mathrm{Pu}$ are present as expected. 


\subsubsection{Processing Analysis}

As processing is conducted in H Canyon adjustments may be needed. Sample points that require processing analysis are conducted to ensure that any necessary modifications to be made to the tank solutions are known. Specifically for AFS-2 in H Canyon, a processing analysis is conducted after the addition of aluminum nitrate following dissolution. The aluminum nitrate is added to complex any fluoride present. This is a corrosion precaution that is common when processing in stainless steel tanks.

Analyses for processing analysis includes free acid, fluoride, boron, $\mathrm{U}$ by Chemcheck, Pu IDMS, Pu isotopic and aluminum analysis. All analyses except aluminum have been previously described and are conducted in the same manner. Aluminum analysis is conducted using ICP-AES. The presence of aluminum indicates the ability of aluminum to remove fluoride from solutions and therefore a certain amount is expected. Furthermore, uranium and plutonium analyses which show the amount of those materials present at particular sample points, gives a greater sense of the efficiency of the processing. If limits on efficiency are not met, further processing such as longer dissolutions or more solvent extractions must be implemented.

\subsubsection{Waste Analysis}

As column and filtrate waste streams are sent back to H Canyon, they must be processed correctly. Upon processing, the final resulting waste streams to be sent to the tank farm are analyzed using waste analysis. It is important to have a correct evaluation of the material being sent for permanent storage as waste. Alpha and gamma activity levels for stored waste cannot exceed tank farm waste acceptance criteria (WAC) limits. Furthermore, waste prepared for tank farm storage must be of a certain composition in terms of waste stream characterization.

Waste analyses consist of free acid, aluminum, ammonium, silicon, nitrate/nitrite ion, alpha and gamma analysis. Free acid and aluminum analyses are conducted in the same manner as previously described. Ammonium analysis is conducted by ISE. The presence of ammonium is related to the possible presence of ammonium nitrate which has the ability to decompose exothermically, producing gases. If a sufficient quantity of ammonium nitrate is collected, there is a potential for an explosion to occur, initiated by high temperatures or large impact. Therefore, safety limits are set for the allowed amount of ammonium present. Silicon analysis is conducted by ICP-AES and is necessary for waste characterization before waste is sent to the tank farm. Nitrate/nitrite ion analysis is conducted using ion chromatography. The correct ratio of nitrate to nitrite ions provides for corrosion control limits to be met and therefore must be monitored and maintained at a certain level before storage. Lastly, alpha analysis is conducted using an alpha spectrometer, while gamma analysis is conducted using a gamma spectrometer. Alpha and gamma counts must be known in order to comply with WAC limits before removal of waste to the tank farm.

\subsection{SUMMARY}

Sample analyses conducted by $\mathrm{F} / \mathrm{H}$ Labs allow for multiple ways to check the processing occurring in $\mathrm{H}$ Canyon and put the Canyon under constant inspection. However, it is necessary to perform multifaceted testing as H Canyon's operations would be inefficient and possibly dangerous without them. The variety of methods available to be performed by the analytical labs extends even further 
than what is previously described. Just as H Canyon is flexible and capable of taking on innumerous missions, $\mathrm{F} / \mathrm{H}$ Labs has many intricate and adaptable methods for analyzing samples from new and ever changing missions. H Canyon is fortunate to have the aid of the F/H Analytical Labs with such capabilities that perceptibly match that of its own.

\subsection{ASPECTS OF INTERNSHIP}

\subsection{PROJECT OBJECTIVE}

The objective of my project was to learn about chemical separations processes occurring on site as well as how they correspond with analyses done by the analytical labs. Furthermore, there was a need for a managerial tool to be created to optimize available space in the analytical labs for upcoming missions. Upon meeting with multiple engineers and management as well as taking a tour of $\mathrm{H}$ Canyon and HBL, I was able to gain an understanding of how the processes are operated and analyzed. The completion of a managerial tool was possible once analyses occurring in all radio hoods, radio benches and glove boxes were recorded.

\subsection{CHEMICAL ENGINEERING CLASSES}

There were a couple of chemical engineering (CE) courses that readily applied to this internship. The main course was CE 407, Separations. The processes occurring in H Canyon are extremely similar to ones studied in class, particularly liquid-liquid extractions occurring with multiple stages. Column extractions, stripping of impurities, and flashpoint analysis are just a few of the methods used in the labs for analysis. Furthermore, understanding of how liquid nuclear materials were transferred in pipes without pumps was easier upon taking CE 317 and CE 318, Transport Processes I and II. This transfer was possible through steam power and use of a venture to create a vacuum. CE 433, Materials Science and Engineering, was helpful in understanding some of the materials used for containment of the nuclear materials. CE 327 and CE 328, Chemical Engineering Lab I and II, were useful in terms of understanding lab analysis and procedures. Further chemistry courses such as CHE 334, Physical Chemistry for Chemical Engineers, were essential in understanding instrumentation in the labs such as ICP-AES, ICP-MS, and TIMS. I believe that much of the processes that I learned about will furthermore apply to CE 434, Chemical Systems and Control, and CE 408, Chemical Engineering Plant Design.

\subsection{BROADER IMPACT}

The broader impact of work done in $\mathrm{H}$ Canyon and $\mathrm{F} / \mathrm{H}$ Labs is seen in impacts on society, contemporary issues, ethics and especially safety. H Canyon is the only radiochemical processing facility in the United States currently capable of handling the recovery and purification of nuclear material on such a large level. F/H Labs are the only facility set up to aid in these efforts. This unique work area encounters many dilemmas and issues that most other chemical processing facilities never would.

\subsubsection{Society Impacts}

$\mathrm{H}$ Canyon and $\mathrm{F} / \mathrm{H}$ Labs have had several impacts on society through the processing that has been performed since its construction. During the cold war, nuclear materials processed for reuse were 
made in H Canyon which was highly efficient. The Soviet Union's inability to keep up with the arms race was its downfall and led to the end of the war. This impacted society by allowing the American people to have a better sense of security once the war was over. Furthermore, the NASA missions that benefited from $\mathrm{H}$ Canyon and HBL processing are currently impacting society in increasing our knowledge about a world outside of our own.

The processing of weapons-grade plutonium to begin at $\mathrm{H}$ Canyon in the fall will have great society impacts as well. This plutonium is to be processed, made into an oxide, and soon after sent to the MFFF facility to be converted into commercial fuel. This ideal of making fuel out of weapons is a concept termed 'swords to plowshares' where these potentially dangerous materials are used for a purpose helpful to society.

Likewise, nuclear fuel is different from other fuels in that it can be recycled. When running a nuclear reactor, approximately five percent of nuclear materials in fuel rods are used before fission products inhibit efficiency. This means that ninety-five percent of the material can be reused if it is reprocessed and rid of those impurities. H Canyon has the unique capability to process spent fuels in this very way.

\subsubsection{Contemporary Issues}

Contemporary issues from $\mathrm{H}$ Canyon processing with coordination of $\mathrm{F} / \mathrm{H}$ Labs are numerous.

One of the more controversial issues directly affecting $\mathrm{H}$ Canyon is the storage of nuclear materials in the form of vitrified waste at Yucca Mountain which was cancelled in 2009. H Canyon processes waste, purifying it before it is turned into its glass form at DWPF. The Blue Ribbon Commission is currently in charge disposal options for UNF located at many governmental as well as commercial sites. The proper disposal of UNF is important to maintain safety and proper containment of materials potentially hazardous to the environment. Any unburied waste is susceptible to natural disasters as evident by the recent Fukushima event in Japan.

One of the alternatives to burial of spent fuel is the disposition of uranium and plutonium by reprocessing for fuel. In the 1990s, the United States and Russia agreed to a recommendation known as the Spent Fuel Standard involving weapons-grade plutonium. This non-proliferation agreement allowed for the disposition of plutonium currently in possession by both countries and is important in reducing 'the clear and present danger of theft of nuclear materials'. In 2002, it was agreed upon that a Mixed Oxide (MOX) facility would be built in both the US and Russia in order to comply with the Spent Fuel Standard. As discussed previously, H Canyon is essential in AFS-2 processing for materials being sent to MFFF, the MOX facility currently being built at SRS. Though Russia's plans to build a MOX facility are currently on hold due to depleted funds, the US continues construction of MFFF at SRS, with a goal of beginning operations in the year 2016.

\subsubsection{Ethics}

SRS brings to mind many ethical dilemmas in its mission statement alone (Environmental Stewardship, Clean Energy, National Security). Environmental concerns are regulated by the South Carolina Department of Health and Environmental Control (DHEC). DHEC holds SRS responsible for complying with federal and state regulations such as the Clean Air Act, the Clean Water Act, Hazardous Waste Regulations, etc. Moreover, DOE has its own environmental monitoring program 
on site. Wildlife and environmental concerns are extensive and take into account the constant analysis of air, water, soil, vegetation, and wildlife for effects by site processes. Additionally, $\mathrm{H}$ Canyon itself makes conscious efforts towards waste minimization, as well as recovery of solvent, acid, and nuclear materials such as uranium during blend down processing. In this way, SRS fully illustrates ethical dilemmas pertaining to the environment and how they can be managed.

Nuclear energy, according to the site can also be described as a clean energy as it does not contribute significantly to smog, acid rain, or global warming. . The site's initiatives towards nuclear is clearly a conscientious effort to rebuild nuclear energy initiatives in the US. Much of the projects taken on by SRS involved nuclear energy initiatives, such as MOX. As a DOE government funded facility, SRS has a responsibility to use tax payer money for the most promising and necessary missions. Therefore, choosing the right missions for SRS is an ethical dilemma most commonly encountered by management on site.

The possession of nuclear material is an issue of national security that SRS accounts for on a daily basis. Concealing of important information is an ethical dilemma for those with classified information. It is the duty of those with classified information to keep it from getting into the wrong hands. Additionally, many precautions are taken for information deemed unclassified as well. The distribution of site information is monitored and always taken under great scrutiny.

\subsubsection{Safety}

Safety at SRS is a way of life. The ideals towards safety first began when DuPont managed the site when it opened in the 50s. As Westinghouse took over in the $80 \mathrm{~s}$, they took over DuPont's safety conscious attitude that it instilled in its employees. Morning briefings are common at F/H Labs to ensure every aspect of the safety in daily procedures is met. Safety meetings are held multiple times a month where more than just safety at work is discussed. All employees are taught to take safety as seriously at home as they do at work. Employees are encouraged to use actions such as behaviorbased safety (BBS) observations where they get incentives for observing anonymous employees during daily activities on site and then reporting possible breaches of safety. It is also emphasized to all employees that if a new aspect of work or an unsafe condition arises, a 'time out' or 'stop work' action can be called. When this happens, work will not resume until the correct form of action can be agreed upon.

Safety in terms of radiation is also an important aspect to working at the site. H Canyon was built to reduce any radioactive exposure, while procedures in both the canyon and the labs are carried out in a precise and cautious manner. The possibility for radiation is a common concern for those working in F/H Labs due to working directly with $\mathrm{H}$ Canyon samples. Radiation limits on labs as well as the units in the lab must not be exceeded, nor can workers exceed their annual radiation dose. This does not mean that the workers receive a much larger dose of radiation while on site; however the lab always takes into account the possibility for contamination. Proper personal protective equipment (PPE) is also necessary entering the labs and certain canyon areas. Although much of these radiation limits are just safety precautions, workers take it as seriously as everything else they do in the labs.

Unlike other manufacturing and processing facilities, SRS is not run purely as a business and demonstrates that the safety of those it employs is paramount. SRS employees are proud of their 
safety culture and are quick to show newcomers what it means to work at one of the safest government labs in the country.

\subsection{REFERENCES}

1. Department of Energy and the National Nuclear Security Administration. "MOX fuel fabrication facility Fact Sheet: Reducing a Clear and Present Danger.” Web. July 2012.

http://www.moxproject.com/images/factsheets/reducing.pdf

2. Savannah River Nuclear Solutions. "We are Savannah River Nuclear Solutions.” Web. July 2012. http:/www.savannahrivernuclearsolutions.com/docs/we_are_srns.pdf

3. Savannah River Site. "Facts enterprise SRS: H Canyon.” February 2012. Web. July 2012. http://www.srs.gov/general/news/factsheets/esrs h_canyon.pdf

4. Severynse, T.F., Nuclear Material Processing at the Savannah River Site, WSRC-MS-98-00515, July 1998.

5. Terry Todd. "Introduction to Nuclear Fuel Cycle Separations." Idaho National Labs. August 4, 2009. Web. July 2012.

http://www.cresp.org/NuclearFuelCycleCourseII/Presentations/04_Todd_CRESP_2009_presentation separations_todd.pdf

\subsection{ACKNOWLEDGEMENTS}

I would like to acknowledge Curt Gardner for his constant aid and support. I also wish to acknowledge assistance provided by Matt Nelson throughout my internship.

Daily assistance by Ken Cheeks, Janice Cook and Shermette Upson was greatly appreciated.

Revision advice given by Mike Brisson was also greatly appreciated.

I am particularly grateful for the assistance given by Edward Sadowski, Ronnye Eubanks, and Stephanie Hudlow in helping me further my understanding of $\mathrm{H}$ Canyon processing and lab analysis.

Further acknowledgements are extended to the staff of F/H Analytical Labs for all the help and encouragement they have given over the summer. 